\title{
Clinical Study of Pit and Fissure Morphology and its Relationship with Caries Prevalence in Young Permanent First Molars
}

\author{
Gazalla Altaf ${ }^{1}$, Shalini Garg ${ }^{2}$, Bhavna G Saraf ${ }^{3}$, Neha Sheoran ${ }^{4}$, Aumir Beg ${ }^{5}$, Mehak Anand ${ }^{6}$
}

\begin{abstract}
Aim: To study the various types of pit and fissure morphology in young permanent first molars and their relationship with caries prevalence arch-wise and quadrant-wise.

Materials and methods: Four hundred young permanent first molars in 100 patients between 8 years and 10 years were examined. Teeth were examined using dental caries diagnostic index, decayed missing filled surfaces of permanent first molar (DMFSM1) index per the World Health Organization (WHO) guidelines (2013), and pit and fissure morphology index (Symons, 1996).

Results: It was found that intermediate type of fissures was most prevalent followed by shallow type of fissures. Deep fissures had significantly more caries than intermediate, and shallow had the least incidence of caries, irrespective of the jaw type and arch side. Also, in general, the left side of arch had lesser caries than that in the right side.

Conclusion: It is recommended to seal off the intermediate and deep pits and fissures in children with high risk of caries, and appropriate preventive measures should be taken. Tooth morphology can be used as an indicator to identify the children at high risk, especially in settings where resources are not adequate.
\end{abstract}

Keywords: Dental caries, DMFT, Pit and fissure morphology, Sealants, Young permanent first molar.

Journal of South Asian Association of Pediatric Dentistry (2019): 10.5005/jp-journals-10077-3032

\section{INTRODUCTION}

Dental caries in children affects the hard tissues of the tooth, which is caused by a combination of multiple factors that include tooth morphology, bacteria, etc., and other offending factors including diet and genetic predisposition. Unique morphology of pits and fissure pattern makes them prone to dental caries in permanent dentition. Sealing such tooth surfaces is considered as the most cost-effective way. Due to inadequately trained human and capital and financial underdevelopment in developing countries, dental caries still exist as a major oral health concern. ${ }^{1-3}$

The first molars remain the most common site for caries within a short period after its eruption, which was demonstrated by $\mathrm{McDonalds}^{4}$ and it was also concluded that occlusal caries are often present on first permanent molars affecting all agegroups.,

Moreover, permanent first molar extractions top the data for the rate and incidence of extractions as compared to other teeth. ${ }^{5}$ Since the occlusal surface of young permanent first molars is susceptible to caries and the caries on these surfaces begin soon after the eruption, early sealing is indicated as suggested by Melgar et al. ${ }^{6}$ and supported by various other authors..$^{1-5}$

Traditionally epidemiologic indices have been proposed to evaluate variations in the incidence of new lesions and the progression of the existing dental lesions. These indices produce more proficient ways of assessing change in the status of decay and the degree of improvement can be calculated directly. ${ }^{1,3,6}$

Pit and fissure sealants have been found out to be highly effective at decay prevention, with reduction in the development and progression of caries by greater than $50 \%$. The pathbreaking research by Lussi ${ }^{7}$ clearly demonstrates that sealants can be used
${ }^{1,3-6}$ Department of Pedodontics and Preventive Dentistry, Sudha Rustagi College of Dental Sciences and Research, Faridabad, Haryana, India

${ }^{2}$ Department of Pediatric and Preventive Dentistry, Faculty of Dental Sciences, SGT University, Gurugram, Haryana, India

Corresponding Author: Shalini Garg, Department of Pediatric and Preventive Dentistry, Faculty of Dental Sciences, SGT University, Gurugram, Haryana, India, Phone: +91 9215668621, e-mail: shaloosandeep@gmail.com

How to cite this article: Altaf G, Garg S, Saraf BG, et al. Clinical Study of Pit and Fissure Morphology and its Relationship with Caries Prevalence in Young Permanent First Molars. J South Asian Assoc Pediatr Dent 2019;2(2):56-60.

Source of support: Nil

Conflict of interest: None

therapeutically over noncavitated carious lesions. So whenever in dilemma about occlusal caries diagnosis, if in doubt, seal' should be followed as the 'management strategy. ${ }^{8}$

It is a well-established fact $^{9}$ that the enamel lining of the recently erupted teeth is porous with abundant organic and cellular debris in fissures. Conceptually, the fissure sealants could be locked into this porous zone of the enamel bordering the fissures as it offers a three-dimensional honeycombed structure. For the effective use of fissure sealant, any procedure whatsoever it is must be carried out at the earliest possible time after eruption. 2,3,5,7-10

According to Nango's classification based on the morphology of pits and fissures, five major types of occlusal pits and fissures are described as $\mathrm{U}, \mathrm{V}, \mathrm{I}, \mathrm{IK}$, and Y. Salman ${ }^{11}$ conducted a study to 
understand the occurrence pattern of the different types of occlusal fissure morphology. He found that $\mathrm{V}$ and IK have the maximum percentage, and the percentage was poor for I-type fissure. He concluded that $V$ and $U$ shapes (shallow fissures) have less severity of dental caries, and this finding was in accordance with that of Nagano. ${ }^{12}$

Ideally, it is recommended to apply sealants immediately after tooth eruption to achieve complete obliteration of the fissures. It might appear as an alluring concept, and newer clinicians might adopt it too; however, no historical information is available in literature regarding this. $3,5,7,9$

Thus, this study aims to understand the anatomical features of pits and fissures in posterior teeth, so that timely intervention of sealing of retentive fissures can reduce the occurrence of dental decay in permanent teeth. However, we planned a study to evaluate the relationship of depth of pits and fissures and occurrence of caries as per pit and fissure morphology index and dental caries diagnostic index and also to assess the pit and fissure morphology of permanent first molars in the investigated sample based on Symon's classification which is the most acceptable and reliable. This method is considered to be the most cost-effective and valuable predictor of caries incidence.

\section{Materials and Methods}

\section{Sample Size}

Prior sample size was calculated using G power software (version 3.0).

A sample size of 95 was calculated for Chi-square test, an effect size of 3.2 , an a error probability as $5 \%$, power $80 \%$, and degree of freedom as 2 . This was rounded off to 100 .

\section{Participants}

Parents of the children were fully explained about the study both verbally and through patient information sheet, and written informed consent was obtained.

\section{Ethical Considerations}

Institutional Ethical Clearance was obtained prior to carrying out the study (Letter No. SRCDSR/ACAD/2019/9756).

\section{Inclusion Criteria}

- Patients with all four young permanent first molars fully erupted.

- Children with good general health.

- Children with chronological age of 8-10 years.

- Ready to comply with the study protocol.

\section{Exclusion Criteria}

- Children with long-standing systemic illness and/or on medications for long duration.

- Partially erupted permanent first molars.

- Teeth with pit and fissure sealants.

- Teeth with any developmental anomalies.

\section{Data Collection}

Four hundred young permanent first molars in 100 patients between 8 years and 10 years and who had all the four permanent molars erupted were screened in the institution and pit and fissure morphology were examined and recorded (Table 1). Young permanent first molars were examined using dental caries diagnostic index, DMFSM1 index per WHO guidelines (2013), ${ }^{13}$ and pit and fissure morphology index (Symons 1996). ${ }^{14}$

\section{Calibration of Examiner}

The primary investigator was trained and calibrated for detection of dental caries and detection of pit type and fissure morphology by a senior faculty who was quite experienced in conducting such epidemiological studies. Interexaminer consistency in diagnosing dental caries was assessed using $\kappa$ statistics. The $\kappa$ coefficient for dental caries was calculated as 0.91; and for shallow, intermediate, and deep fissures it was $0.96,0.93$, and 0.89 , respectively.

\section{Dental Examination}

Cotton rolls were used to dry the teeth and fiber-optic light and a mouth mirror were used as illumination methods. Two separate and calibrated examiners diagnosed dental caries and pit and fissure morphology of first molar.

For plaque removal and examination of surfaces, dental probe was used. No radiographs were taken. The recording was done by two trained chairside assistants.

\section{Statistical Analysis}

The data were collected and entered in the Excel sheet using Microsoft Excel Software and was transferred to Statistical Package for Social Sciences version 21 (IBM Inc.) for analysis. Data were subjected to descriptive statistics for calculation of mean, standard deviation, absolute, and relative frequencies. Chi-square test was used to compare the categorical variables. A level of significance was set at 0.05 .

\section{Results}

Four hundred young permanent first molars in 100 patients aged between 8 years and 10 years and who had all the four permanent molars erupted were screened, and the pit and fissure morphology were examined and recorded.

Pit and fissure morphology and caries prevalence were visually examined and compared by two independent examiners (Table 2).

Intermediate fissures were more prevalent (50\%) followed by shallow (38\%) and then deep fissures (12\%), and the dental caries were more in deep fissures followed by intermediate and then shallow fissures (Table 3).

It was also found that the left side of the arch has lesser prevalence of caries than the right side of the arch. Also young

Table 1: Types of pits and fissures (Symons 1996)

\begin{tabular}{ll}
\hline Category & Description \\
\hline Shallow & $\begin{array}{l}\text { Cuspal inclines meet at a wide angle. The } \\
\text { base of the fissure is visible. No visible } \\
\text { clefting between the cuspal inclines } \\
\text { Cuspal inclines meet at an angle narrower } \\
\text { than the designated shallow fissures. The } \\
\text { base of the fissure is usually visible. Clefts } \\
\text { are visible at a uniform width of the fissure } \\
\text { Cuspal inclines meet at a narrow angle. } \\
\text { The base of the fissure is not visible. Slit- } \\
\text { like clefting is visible between the cuspal } \\
\text { inclines }\end{array}$ \\
\hline
\end{tabular}


maxillary permanent first molar with deep fissure is more prone to caries than mandibular first molar with deep fissure (Table 4).

Further it was observed that caries were more prevalent in deep fissures followed by intermediate and then shallow fissures, irrespective of the type of tooth, and the difference was statistically significant ( $p$ value $<0.0001, \mathrm{~S}$ ) (Figs 1 and 2 ).

\section{Discussion}

Young children have pits and fissures susceptible to decay. According to Ripa et al., ${ }^{15}$ enamel in pit and fissures is not able to compensate for plaque accumulation, accordingly protection against caries is less compared to smooth surface caries, confirming the complex morphology of such teeth. Rapid occurrence of dental decay in pit and fissures majorly owes to the fact of proximity of fissure depth to dentino-enamel junction (DEJ) and the dentin underneath that is highly prone to caries. ${ }^{1,2,5-7}$

Many prospective trials have been undertaken to examine the effect of sealing over caries, using clinical, radiographic, and bacterial sampling methods. ${ }^{7,8}$ Most of these studies suggest that caries progression is either slowed down or even arrested under the effect of sealants. ${ }^{5-8,10}$ Quaglio et al. ${ }^{16}$ in his study established the association between clinical parameters and active carious lesions in first permanent molars.

Going et al. ${ }^{17}$ monitored sealed carious lesions in a 5-year study, which included bacterial sampling, and reported $89 \%$ reversal from caries to noncarious, with no effect in all control (nonsealed) sites. Also, 9-year long study was undertaken to study the composite and sealant over caries, by radiographic and clinical analyses and showed caries are arrested in 63 of 75 teeth. $^{2}$

In the study of the contents of fissures to examine their microbial colonization, it was postulated that upper portions contained remarkable number of cocci and bacilli, while as mineralization was seen in the bottom of the fissure along with an amorphous mass with few bacteria. These contents of pit and fissures can be significant in the prevention of caries because sealants are used shortly after eruption of teeth. ${ }^{18}$

Table 2: Overall prevalence of dental caries in three types of fissures (shallow, intermediate, and deep) in young permanent first molars

\begin{tabular}{llll}
\hline Tooth & $\begin{array}{l}\text { Shallow fissures } \\
\text { (\%) }\end{array}$ & $\begin{array}{l}\text { Intermediate } \\
\text { fissures (\%) }\end{array}$ & Deep fissures (\%) \\
\hline 16 & 13.3 & 39.5 & 100.00 \\
26 & 8.8 & 24.6 & 100 \\
36 & 10.3 & 28.8 & 50 \\
46 & 11.6 & 42.9 & 40 \\
Overall & 11.26 & 32.8 & 68.75 \\
\hline
\end{tabular}

The present study was conducted to find the relationship of depth of pits and fissures and occurrence of caries in 8-10-year-old children. Permanent molars are very good and reliable indicators of oral health status of a child because of its unique anatomical status and susceptibility to caries. ${ }^{1}$

Position of permanent molars influence the vertical maxilla and the mandible distance, along with occlusion, and esthetics also bearing the maximum occlusal load in the oral cavity (Vehkalahti et al.). ${ }^{19}$

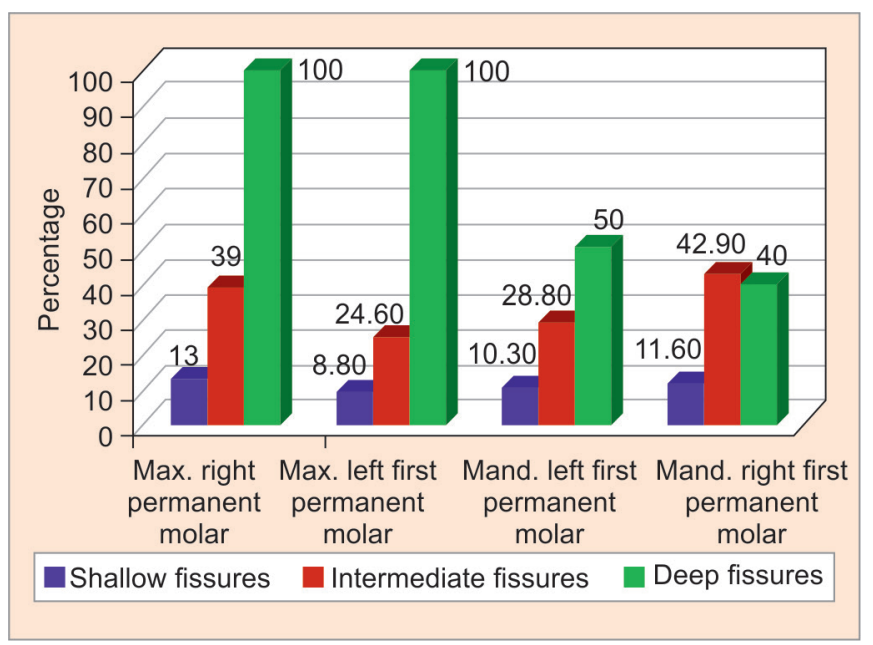

Fig. 1: Prevalence of dental caries according to the type of fissures in young permanent first molars $(16,26,36,46)$

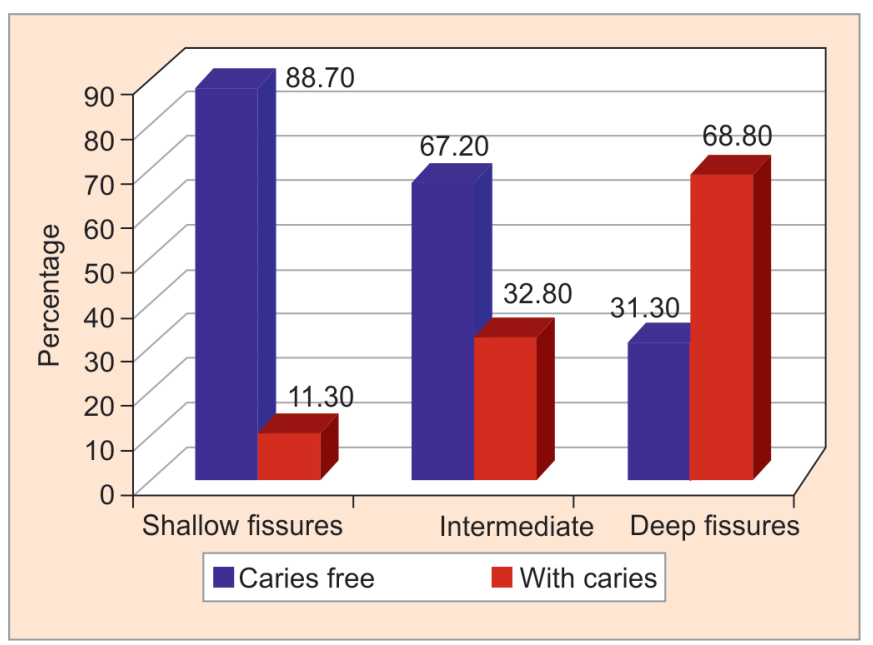

Fig. 2: Overall relationship of pit and fissure morphology with the prevalence of dental caries

Table 3: Prevalence of dental caries according to the type of fissures in young permanent first molars $(16,26,36$, and 46$)$

\begin{tabular}{|c|c|c|c|c|c|c|c|}
\hline \multirow[b]{2}{*}{ Tooth } & \multicolumn{2}{|c|}{ Type I shallow } & \multicolumn{2}{|c|}{ Type II intermediate } & \multicolumn{2}{|c|}{ Type III deep } & \multirow[b]{2}{*}{ Total, carious, $p$ value, $t$} \\
\hline & $n$ & Carious (\%) & $n$ & Carious (\%) & $n$ & Carious (\%) & \\
\hline 16 (total $n=100)$ & 45 & $6(13)$ & 43 & $17(39)$ & 12 & $12(100)$ & $35,(35 \%),<0.001, S$ \\
\hline $26($ total $n=100)$ & 34 & $3(8.8)$ & 57 & $14(24.6)$ & 9 & $9(100)$ & $26,(26 \%),<0.001, \mathrm{~S}$ \\
\hline 36 (total $n=100)$ & 29 & $3(10.3)$ & 59 & $17(28.8)$ & 12 & $6(50)$ & $26,(26 \%),<0.023, S$ \\
\hline 46 (total $n=100)$ & 43 & $5(11.6)$ & 42 & $18(42.9)$ & 15 & $6(40)$ & $29,(29 \%),<0.004, S$ \\
\hline Total $(n=400)$ & 151 & & 201 & & 48 & & \\
\hline Type of fissure & $38 \%$ & & $50 \%$ & & $12 \%$ & & \\
\hline
\end{tabular}


In our study, it was also found that intermediate fissures were more prevalent followed by shallow and then deep fissures. Similar results were reported in the study conducted by Cho and $\mathrm{Kim}^{20}$ in 1989.

In our study, it was found that deep fissures are more prone to caries followed by intermediate fissures but shallow fissures have the least caries (Figs 3 to 5). Similar results were found by Gillins and Bunoucore ${ }^{21}$ in which they found that deep invaginations may sometimes even progress up to the DEJ but with unexposed dentin. The V/U-shaped fissures (shallow fissures) have been found to be self-cleansing and resistant to caries (Sánchez-Pérez et al..). ${ }^{22}$ Also, the complex branch pattern of I/K-type fissures has the deepest fissure morphology, making them the most susceptible caries. $^{12}$

Also, it was found that the left side of the arch has lesser occurrence of caries than the right side of the arch; the possible explanation for this might be as most people are right-handed and tend to clean opposite arch more. Pita et al. confirmed that toothbrushing has a more positive effect on oral health compared to that of a correct diet. They also found that prevalence of caries was lesser in children brushing their teeth multiple times in a day compared to those never brushing. It was also seen that the young maxillary first molar with deep fissures is more prone to caries compared to young mandibular first molars, whereas the advantage of self-cleansing gravity-supported jaw is nullified by retention of food in deep fissures (Farooqi et al.). ${ }^{23}$

Because of the numerous pits of different lengths and line angles, the morphology of occlusal surfaces of molars becomes variable and unique in different cases as demonstrated by Juhl. ${ }^{24}$ Fejerskov ${ }^{25}$ suggested that dental caries is highly preventable by proper and timely preventive measures.

Appropriate preventive measures for deep pit and fissures should be instituted and sealants should be used for patients with high risk of caries. However, the morphology of teeth can be used as an effective indicator to identify young patients at high risk of caries, particularly in restricted settings.

Table 4: Overall relationship of pit and fissure morphology with the prevalence of dental caries

\begin{tabular}{llllll}
\hline & & \multicolumn{3}{c}{ Caries } & Total \\
\cline { 3 - 5 } & & & Absent & Present & 17 \\
Type of fissure & Shallow & $n$ & 134 & 11.3 & 100.0 \\
& & $\%$ & 88.7 & 66 & 201 \\
& Intermediate & $n$ & 135 & 32.8 & 100.0 \\
& & $\%$ & 67.2 & 33 & 48 \\
Total & $n$ & 15 & 68.8 & 100.0 \\
& & $\%$ & 31.3 & 116 & 400 \\
$p$ value & $n$ & 284 & 29.0 & 100.0 \\
\hline S & & & & & \\
\hline
\end{tabular}

S, significant
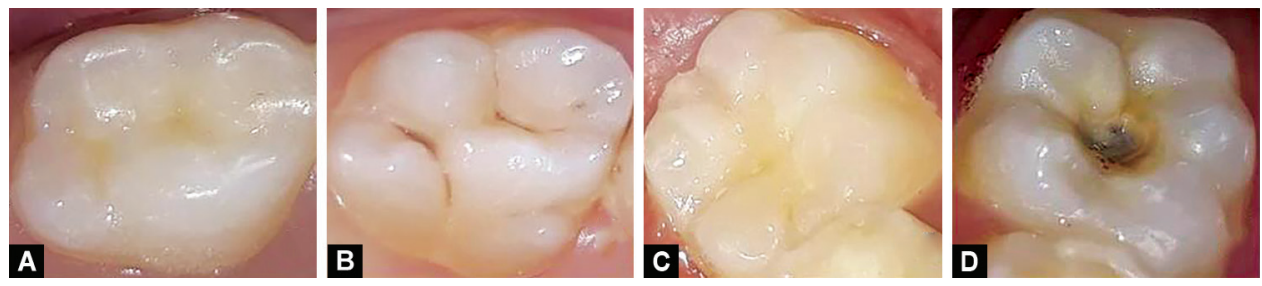

Figs 3A to D: Shallow fissures of maxillary first permanent molar: (A) Without caries; (B) With caries. Shallow fissures of mandibular first permanent molar: (C) Without caries; (D) With caries
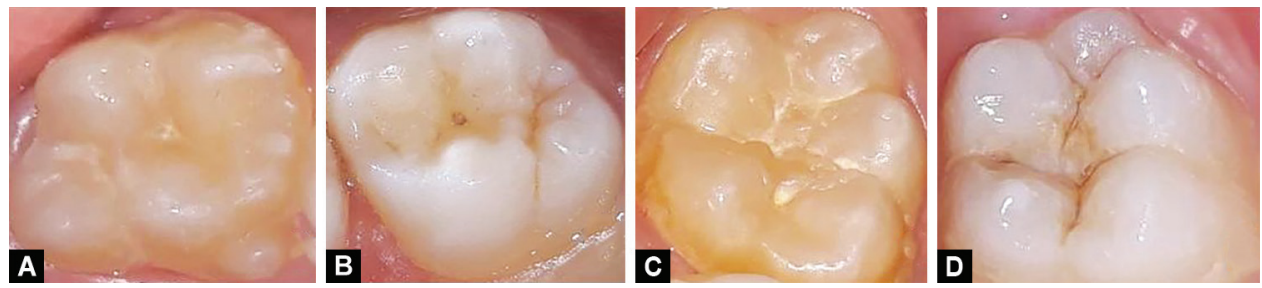

Figs 4A to D: Intermediate fissures of maxillary first permanent molar: (A) Without caries; (B) With caries. Intermediate fissures of mandibular first permanent molar: (C) Without caries; (D) With caries 

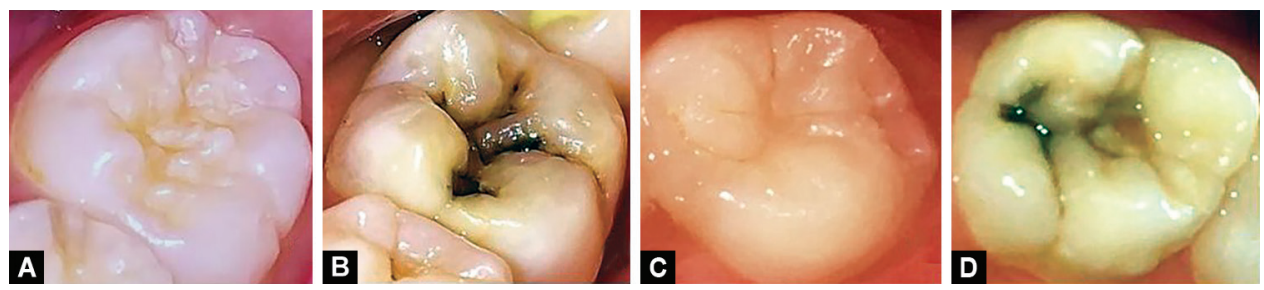

Figs 5A to D: Deep fissures of mandibular first permanent molar: (A) Without caries; (B) With caries. Deep fissures of maxillary first permanent molar: (C) Without caries; (D) With caries

\section{Conclusion}

- Prevalence of caries increases with increase in complexity and depth of fissure pattern, i.e., deep > intermediate $>$ shallow, but the difference was not significant in deep and intermediate types of fissure.

- Also, occurrence of caries in first molars is more related to past caries experience.

- Proper case history should be recorded and any positive history about susceptibility of caries should be acted upon, by using sealants.

- Caries is a multifactorial disease. Sealing deep and intermediate fissures may help to make caries susceptible to tooth surface that is less prone to caries.

- The primary dental healthcare provider should be aware of the significance of pit and fissure morphology and should be able to adopt the appropriate preventive strategies for the young patients.

- Dental health screening and checkup camps can be instrumental in identifying the children with high risk of caries on the basis of fissure morphology.

\section{REFERENCES}

1. Desai VC. Prevalence of dental caries in first and second permanent molars. Int J Res Med Sci 2014;2(2):514-520. DOI: 10.5455/2320-6012. ijrms20140528.

2. Deery C. Caries detection and diagnosis, sealants and management of the possibly carious fissure. Br Dent J 2013;214(11):551-557. DOI: 10.1038/sj.bdj.2013.525.

3. Khanna R, Pandey RK, Singh N. Morphology of pits and fissures reviewed through scanning electron microscope. Dentistry 2015;5(4):1. DOI: 10.4172/2161-1122.1000287.

4. McDonald SP, Sheiham A. The distribution of caries on different tooth surfaces at varying levels of caries - a compilation of data from 18 previous studies. Community Dent Health 1992;9(1):39-48.

5. Chukwu GA, Adeleke OA, Danfillo IS, et al. Dental caries and extraction of permanent teeth in Jos, Nigeria. Afr J Oral Health 2004;1(1):31-36. DOI: 10.4314/ajoh.v1i1.31302.

6. Melgar RA, Pereira JT, Luz PB, et al. Differential impacts of caries classification in children and adults: a comparison of ICDAS and DMF-T. Br Dent J 2016;27(6):761-766. DOI: 10.1590/01036440201600990.

7. Lussi A. Validity of diagnostic and treatment decisions of fissure caries. Caries Res 1991;25(4):296-303. DOI: 10.1159/000261380.

8. Mitchell JK, Furness AR, Sword RJ, et al. Diagnosis of pit-andfissure caries using three-dimensional scanned images. Oper Dent 2018;43(3):E152-E157. DOI: 10.2341/17-076-L.

9. Grewal N, Chopra R. The effect of fissure morphology and eruption time on penetration and adaptation of pit and fissure sealants: an SEM study. J Indian Soc Pedod Prev Dent 2008;26(2):59-63. DOI: 10.4103/0970-4388.41617.
10. Zeng Z, Shaffer JR, Wang X, et al. Genome-wide association studies of pit-and-fissure- and smooth-surface caries in permanentdentition. J Dent Res 2013;92(5):432-437. DOI: 10.1177/0022034513481976.

11. Salman FD. The effect of fissure morphology on caries severity of adults in north Iraq. Al-Taqani 2011;24(4):29-37.

12. Nagano T. Relation between the form of pit and fissure and the primary lesion of caries. Dent Abstr 1961;6:426.

13. Katge $F$, Rusawat $B$, Shitoot $A$, et al. DMFT index assessment, plaque $\mathrm{pH}$, and microbiological analysis in children with special health care needs, India. J Int Soc Prev Community Dent 2015;5(5):383-388. DOI: 10.4103/2231-0762.164790.

14. Wang JD, Chen X, Frencken J, et al. Dental caries and first permanent molar pit and fissure morphology in 7-to 8-year-old children in Wuhan, China. Int J Oral Sci 2012;4(3):157-160. DOI: 10.1038/ijos. 2012.34.

15. Ripa LW, Leske GS, Varma AO. Longitudinal study of the caries susceptibility of occlusal and proximal surfaces of first permanent molars. J Public Health Dent 1988;48(1):8-13. DOI: 10.1111/j.17527325.1988.tb03154.x.

16. Quaglio JM, Sousa MB, Ardenghi TM, et al. Association betweenclinical parameters and the presence of active caries lesions in first permanent molars. Braz Oral Res 2006;20(4):358-363. DOI: 10.1590/ S1806-83242006000400014.

17. Going RE, Loesche WJ, Grainger DA, et al. The viability of microorganisms in carious lesions five years after covering with a fissure sealant. J Am Dent Assoc 1978;97(3):455-462. DOI: 10.14219/ jada.archive.1978.0327.

18. Galil KA, Gwinnett AJ. Human tooth-fissure contents and their progressive mineralization. Arch Oral Biol 1975;20(9):559-562. DOI: 10.1016/0003-9969(75)90074-6.

19. Vehkalahti MM, Solavaara L, Rytömaa I. An eight-year follow-up of the occlusal surfaces of first permanent molars. J Dent Res 1991;70(7):1064-1067. DOI: 10.1177/00220345910700071001.

20. Cho J, Kim DK. Study on the shape and depth of the occlusal central fissure in permanent molar teeth. Taehan Chikkwa Uisa Hyophoe Chi 1989;27(10):959-964.

21. Gillings B, Buonocore M. Thickness of enamel at the base of pits and fissures in human molars and bicuspids. J Dent Res 1961;40:119-133. DOI: $10.1177 / 00220345610400010301$.

22. Sánchez-Pérez L, Irigoyen-Camacho ME, Molina-Frechero N, et al. Fissure depth and caries incidence in first permanent molars: a five-year follow-up study in schoolchildren. Int J Environ Res Public Health 2019;16(19):3550. DOI: 10.3390/ ijerph16193550.

23. Faroogi FA, Khabeer A, Moheet IA, et al. Prevalence of dental caries in primary and permanent teeth and its relation with tooth brushing habits among schoolchildren in Eastern Saudi Arabia. Saudi Med J 2015;36(6):737-742. DOI: 10.15537/smj.2015.6. 10888.

24. Juhl M. Three-dimensional replicas of pit and fissure morphology in human teeth. Scand J Dent Res 1983;91(2):90-95. DOI: 10.1111/j.16000722.1983.tb00782.x.

25. Fejerskov $\mathrm{O}$. Changing paradigms in concepts on dental caries: consequences for oral health care. Caries Res 2004;38(3):182-191. DOI: $10.1159 / 000077753$. 